ESPAÇO ABERTO

\title{
Por que precisamos da diferenciação pedagógica? Ensaio sobre a individualização e seus paradoxos
}

Roberto Rafael Dias da Silva' (D) Renata Porcher Scherer'

RESUMO

O presente ensaio busca problematizar a questão "Por que precisamos da diferenciação pedagógica?”, considerando o debate educacional estabelecido no decorrer do século XX acerca da individualização. Alvo de críticas bastante severas, assim como bandeira de luta de movimentos que apregoam a inovação pedagógica, o conceito de individualização carece de uma reflexão interdisciplinar que efetivamente o mantenha no campo da controvérsia. Ao longo do ensaio, defende-se que a ênfase exclusiva na sociedade pode se converter em violência (na forma dos variados totalitarismos engendrados no século XX), ao mesmo tempo que a ênfase exclusiva no indivíduo, além de pedagogicamente irresponsável, bloqueia as possibilidades de diálogo, a convivência democrática e a constituição de uma pauta formativa comum.

PALAVRAS-CHAVE

educação; diferenciação pedagógica; individualização.

"Universidade do Vale do Rio dos Sinos, São Leopoldo, RS, Brasil. 


\section{WHY DO WE NEED PEDAGOGICAL DIFFERENTIATION? AN ESSAY ON INDIVIDUALIZATION AND ITS PARADOXES}

\section{ABSTRACT}

This essay seeks to problematize the question "Why do we need pedagogical differentiation?," considering the educational debate established during the 20th century about individualization. Targeted by quite severe criticisms, as well as a movements strive flag that proclaim pedagogical innovation, the concept of individualization requires an interdisciplinary reflection that effectively maintains it in the field of controversy. Throughout the essay it is argued that an exclusive emphasis on society can be turned into violence (in the form of the various totalitarianisms engendered in the 20th century), while an exclusive emphasis on the individual, besides being pedagogically irresponsible, blocks the possibilities of dialogue, democratic coexistence and the constitution of a common formative agenda.

KEYWORDS

education; pedagogical differentiation; individualization.

\section{¿POR QUÉ NECESITAMOS LA DIFERENCIACIÓN PEDAGÓGICA? ENSAYO SOBRE LA INDIVIDUALIZACIÓN Y SUS PARADOJOS}

\section{RESUMEN}

El presente ensayo busca problematizar la cuestión “¿Por qué necesitamos la diferenciación pedagógica?”, considerando el debate educativo establecido durante el siglo XX acerca de la individualización. Foco de críticas muy severas, así como bandera de lucha de movimientos que pregonan la innovación pedagógica, el concepto de individualización necesita una reflexión interdisciplinaria que efectivamente lo mantenga en el campo de la controversia. A lo largo del ensayo se defiende que un énfasis exclusivo en la sociedad puede convertirse en violencia (en la forma de los variados totalitarismos engendrados en el siglo XX), al mismo tiempo que un énfasis exclusivo en el individuo, además de pedagógicamente irresponsable, bloquea las posibilidades de diálogo, convivencia democrática y de constitución de una pauta formativa común.

PALABRAS CLAVE

educación; diferenciación pedagógica; individualización. 


\section{INTRODUÇÃO}

Para entrar no novo mundo, urge dar vida àqueles atores que, por um lado, determinam a consciência coletiva de ser parte integrante do mesmo momento bistórico, e, por outro, sublinham a vontade de cada indivíduo de defender sua identidade própria, ou seja, sua diferença

(Touraine, 2011, p. 66)

No decorrer das últimas décadas, as pesquisas em educação têm apresentado os perigos da intensificação de processos cada vez mais individualizados de formação dos estudantes. Já no fim da década de 1970, por exemplo, o pedagogo José Mário Pires Azanha (2004) apontava para os dilemas da democratização escolar alertando para duas formas distintas de como o conceito de democracia estava sendo apropriado pelo campo educacional. Uma primeira forma teria relação com as condições de acesso e permanência da educação para todos, e a outra vinculava-se à expressão da liberdade dos estudantes. Para o pedagogo, dessa forma, o entendimento e a tradução das teorias educacionais do conceito de democratização como prática de liberdade poderiam ter produzidos degradação, no sentido pedagógico, da concepção de democracia política. Nas palavras do autor, observa-se que as pedagogias libertárias, mesmo não pretendendo, poderiam ter contribuído para deslocar "a democratização do ensino do plano de criação de um espaço público de participação social para o plano individual de formação da vontade" (Azanha, 2004, p. 343).

Contemporaneamente, tais análises e críticas aos processos de individualização do ensino centrado em uma suposta liberdade de escolha dada aos estudantes parecem ter se intensificado e assumido novos contornos. Por uma análise da individualização dos processos formativos via estratégias curriculares (Silva, 2014; Scherer e Gräff,2017), processos de avaliação (Scherer, 2017), deslocamento do ensino para aprendizagem (Biesta, 2013,2016; Masschelein e Simons, 2014a, 2014b) ou mesmo dos contornos da autoridade (Aquino, 2014), tais estudos afirmam que a função docente parece se esmaecer com o fortalecimento de propostas pedagógicas cada vez mais individualizantes centradas no interesse de cada aluno em detrimento de uma pauta formativa comum, porém gostaríamos de chamar atenção neste artigo para um aspecto que parece silenciado nas discussões e críticas sobre a individualização dos percursos pedagógicos dos estudantes e de uma pauta formativa centrada nos interesses e nas necessidades deles.

Como bem exploraram os estudos citados anteriormente, muitos são os problemas derivados dessa inversão da centralidade dos processos pedagógicos de uma pauta coletiva para um trabalho cada vez mais individualizado e, concomitantemente, de uma supressão da relação assimétrica estabelecida entre professores e alunos. Todavia, o elemento que nos parece silenciado nesse debate é a importância do respeito ao indivíduo como condição para o estabelecimento de uma escola democrática. Sendo assim, no decorrer deste ensaio exploramos como o debate entre o universal e o particular tem sido delineado por diferentes áreas do saber e apontamos para os perigos tanto de uma pauta pedagógica que se constitui tomando como referência apenas o indivíduo com suas necessidades 
e desejos como de uma proposta educativa que não considera as necessidades individuais dos estudantes produzindo uma ação educativa padronizada (e, muitas vezes, segregacionista).

Em uma leitura mais ampliada das teorizações pedagógicas contemporâneas, temos, pelo menos, duas posições predominantes no que se refere à questão da individualização. De um lado, encontramos a tendência a reduzir o trabalho escolar ao nível do desenvolvimento dos estudantes, seja enfatizando o âmbito cognitivo, seja priorizando o âmbito das escolhas individuais. Nessa tendência, escola boa é aquela que promove o desenvolvimento dos estudantes por meio de suas escolhas individuais, valendo-se sobretudo de procedimentos lúdicos e criativos. De outro lado, temos aqueles que reivindicam uma retomada do potencial político e epistemológico da forma-escola. Em sua percepção, seria desejável suspender as diferenças para garantir as condições de uma escola mais democrática.

Pelo que podemos constatar, não se trata de uma questão de simples resolução. Aliás, paralelamente a esse debate deparamos com a principal aporia da composição do discurso pedagógico: as tensões entre o universal e o particular. Reconhecemos que aceitamos debater uma questão polêmica e nossa intenção, para esse momento, é efetivamente mantê-la no plano da controvérsia. Mesmo que ao final consigamos esboçar algumas respostas, o maior exercício proposto para aqui é exercitar a arte da problematização.

Ao nos propormos, neste texto, realizar um exercício de problematização pensando na tensão existente no discurso pedagógico entre o universal e o particular, buscamos inspiração nos trabalhos foucaultianos com base na atividade filosófica. Para o pensador, filosofar consistiria no "trabalho crítico do pensamento sobre o próprio pensamento" (Foucault, 2014, p.14) e no exercício de "tentar saber de que maneira e até onde seria possível pensar diferentemente em vez de legitimar o que já se sabe" (Foucault, 2014, p. 14). Em decorrência disso, nosso texto constitui-se em um ensaio que para o filósofo seria uma "experiência modificadora", e não uma apropriação simplificadora para fins de comunicação. O ensaio para Foucault (2014, p. 14) "é o corpo vivo da filosofia”, desde que seja "um exercício de si, no pensamento". Assim sendo, anunciamos a questão estruturadora do presente ensaio: por que precisamos da diferenciação pedagógica?

Diante dessas observações iniciais, sinalizamos que organizamos o presente ensaio em três partes. Na primeira parte, realizamos uma retomada da crítica social contemporânea acerca dos processos de individualização da modernidade, valendo-nos de uma abordagem pluralista que assume como tarefa intelectual repensar a formação humana, sobretudo aquela que acontece na escola. A seguir, na segunda parte, contextualizamos a questão orientadora dessa problemática na literatura pedagógica do século XX, lançando mão de duas tradições importantes para a democratização da escola pública no Ocidente: os leitores da escola republicana francesa e as formas institucionais dela derivadas, bem como dos desenvolvimentos curriculares posteriores ao movimento escolanovista. Ao final, na terceira parte deste ensaio, traçamos algumas linhas de reflexão para pensar a questão contemporaneamente, por uma perspectiva pedagógica. 


\section{A INDIVIDUALIZAÇÃO EM PERSPECTIVA: DELINEANDO UM PARADOXO}

Para compreender e complexificar o que neste texto nomeamos de os paradoxos da individualização, nesta seção revisamos algumas formulações do pensamento social contemporâneo, sobretudo no que tange aos processos de socialização, subjetivação e individualização engendrados a partir da segunda metade do século XX. Alain Touraine, em sua conhecida obra Pensar outramente, destaca: "O respeito do indivíduo é condição para o respeito dos direitos sociais e culturais e é, por consequência, a condição da democracia” (Touraine, 2009, p. 33). O pensador, ao refletir sobre a importância do respeito ao indivíduo como condição para a democracia, aponta para a atualidade de complexificarmos nossa compreensão de liberdade distinguindo o que ele denomina de liberdade positiva e liberdade negativa.

Touraine (2009) utiliza o exemplo das religiões para explorar essas diferentes compreensões do conceito de liberdade. Assim, a liberdade positiva teria relação com o direito daqueles que querem praticar livremente uma religião, enquanto a liberdade negativa consistiria na liberdade de não a praticar, de não ter qualquer pertença religiosa e de, até mesmo, ter a liberdade de abandonar uma igreja. Por essa perspectiva, a liberdade de não praticar, além de ser tão importante quanto as práticas positivas, "está no coração da liberdade. Não existe liberdade de práticas se não existe a liberdade de não fazê-lo, de não integrar-se" (Touraine, 2009, p. 132). Com essa análise, Touraine (2009) convida-nos a pensar que os direitos culturais podem se transformar em deveres e na ausência total de escolha, e a única forma para nos desviarmos desse perigo seria a garantia de uma liberdade negativa, ou seja, a liberdade de não participar.

No interior desse diagnóstico, acreditamos na importância de pensar sobre os limites do individualismo, sendo esta uma questão teórica importante para compreendermos e nos posicionarmos de maneira crítica ante os processos cada vez mais intensos de individualização da pauta formativa dos estudantes. Alain Renaut, por sua vez, na obra $O$ individuo esclarece que historicamente as teorias marxistas têm nos auxiliado a reinterpretar a lógica global da modernidade olhando para os "fenômenos sociais e culturais em termos de crescente alienação em relação ao coletivo" (Renaut, 1998, p. 20). Somente nos anos de 1980, conforme o autor, após uma crise do marxismo, emergiriam teorizações de vertente neotocquevilliana que nos ofereceriam ferramentas para interpretar a história da modernidade, "não a partir do desenvolvimento do modo de produção capitalista, mas de acordo com uma dinâmica de emancipação do indivíduo em relação ao fardo das tradições e das hierarquias naturais" (Renaut, 1998, p. 20).

Essa mudança de paradigma explicativo da modernidade — de uma lógica da alienação de vertente marxista para uma de emancipação individual de vertente tocquevilliana - é denominada pelo filósofo de "paradigma individualista”. Mesmo que ele registre a importância desse paradigma, aponta para algumas inquietações no que tange a esse conjunto de estudos e pergunta se eles não estariam contribuindo para a produção de uma "nova cegueira a respeito da complexidade do moderno" (Renaut, 1998, p. 22). Para refletir sobre o estabelecimento de uma cultura democrática 
e os processos de individualização, Renaut (1998) opta por revisitar o pensamento de Tocqueville no que se refere às suas análises da modernidade. Dessa forma, afirma que "a dinâmica da democratização pode identificar-se inteiramente com a afirmação do indivíduo enquanto princípio e ao mesmo tempo enquanto valor" (Renaut, 1998, p. 25).

Para Tocqueville, valendo-nos dessa leitura, o individualismo moderno estabelecer-se-ia haja vista duas principais características. A primeira consistiria na revolta dos indivíduos contra a hierarquia em nome da igualdade. Logo, a luta pela igualização das condições teria sido traduzida contra qualquer forma de hierarquia. A segunda característica teria relação com a denúncia das tradições em nome da liberdade. Tais sociedades, ao compreenderem a tradição como uma imposição ao indivíduo sem ter sido por ele escolhida, nem por ele fundada, se oporiam à tradição em defesa da liberdade dos indivíduos.

Ao assinalar tal problemática, Tocqueville focaliza nos possíveis efeitos dessa dinâmica individualista, na qual a hierarquia era posicionada como oposição à igualdade e tradição como contrária de liberdade. Perguntamo-nos se tal paradoxo apontado por Tocqueville não estaria no epicentro do paradoxo dos processos de individualização no campo pedagógico, que em nome da igualdade suprimimos qualquer hierarquia esmaecendo uma relação assimétrica entre professor e aluno e também em nome da liberdade nos posicionaríamos contrários a qualquer forma de tradição ${ }^{1}$.

Seguimos tal reflexão com uma questão que Renaut (1998) nos lança no tocante às análises realizadas por Tocqueville: "Como encontrar no seio de um universo democrático e, portanto, individualista, freios para a decomposição do tecido social e contrapoderes que se possam opor ao Estado?" (Renaut, 1998, p. 33). A tensão entre o universal e o particular parece se constituir nesse emblemático debate que o autor apresenta acerca das condições para o estabelecimento de uma sociedade democrática que respeite e valorize o indivíduo sem, entretanto, condenar determinadas relações sociais. Em nossa percepção, este é o grande paradoxo das pedagogias contemporâneas, tal como exploramos mais adiante.

De acordo com o sociólogo Danilo Martuccelli (apud Nobile e Ferrada, 2015, p.101), em entrevista recente, refletir sobre os processos de fabricação dos indivíduos no contexto da América Latina implica considerar algumas diferenças específicas em relação aos processos ocorridos nas sociedades europeias e norte-americanas. Enquanto nos países do Norte teria ocorrido um processo de individualismo institucional, no qual "as instituições fazem de cada indivíduo um modelo, lhe dão insumos, suportes, recursos e o indivíduo se fabrica como indivíduo a partir de uma prescrição institucional” (Martuccelli apud Nobile e Ferrada, 2015, p. 101); na América Latina o direito individual se formou como princípio de base para o pensamento republicano por meio das próprias constituições desses países. Nas sociedades latino-americanas, por conta da fragilidade dos mecanismos de proteção

1 Acerca do declínio das relações assimétricas, em perspectiva pedagógica, encontramos desdobramos importantes na obra de Narodowski (2016). 
social derivados de suas incipientes formas estatais, constituíram-se hiperindivíduos mobilizados para atender às demandas da vida individual e coletiva, capazes de resolver por si mesmos as questões que no contexto europeu eram garantidas pelos Estados nacionais. Em outras palavras, de acordo com Martuccelli (apud Nobile e Ferrada, 2015), na América Latina a formação do indivíduo teria sido anterior à composição dos Estados modernos.

Quer dizer, o indivíduo é um hiper-indivíduo que tem que resolver por ele mesmo, através de suportes que ele mesmo constrói - muitos familiares um conjunto de proteções indispensáveis para poder existir na sociedade. Aquilo que no norte transmitem as instituições, no sul tens que fazer por ti mesmo. (Martuccelli apud Nobile e Ferrada, 2015, p. 102)

O sociólogo, com tais apontamentos, além de nos ajudar a compreender que os contornos da individualização precisam ser analisados levando em conta as diferenças desse processo em nossas sociedades latino-americanas, aponta para alguns paradoxos a fim de que entendamos a individualização por uma análise dicotômica - delineada pela defesa ou pela acusação. Segundo o autor, uma instituição, seja ela um hospital, seja um tribunal ou uma escola, é considerada injusta quando se torna incapaz de tratar com o mínimo grau de singularização as condições particulares dos indivíduos, criando uma utopia institucional que categoriza como adequadas as instituições que conseguem tratar individualmente, ou seja, de modo diferencial cada ator particularmente. O problema é que tal utopia institucional se torna uma verdade apenas para os mais ricos, que possuem um tratamento altamente individualizado. Dessa forma, parece que a "singularidade em vez de uma utopia se torna uma experiência [exclusiva] para os mais ricos" (Martuccelli apud Nobile e Ferrada, 2015, p. 103). Com tal diagnóstico sociológico, o pesquisador encaminha-se para mostrar os perigos a serem enfrentados nas sociedades que fazem da singularidade seu horizonte de justiça. Segundo Martuccelli (apud Nobile e Ferrada, 2015), a principal e mais grave consequência a ser enfrentada por esse processo de singularização extrema pode ser colocar em questão as bases da igualdade sob as quais nossas sociedades foram constituídas. Nas palavras de Martuccelli (apud Nobile e Ferrada, 2015, p. 103), "entre a igualdade e a singularidade pode existir um círculo virtuoso, mas também podem existir muitas contradições perigosas".

De acordo com Touraine (2011), mais uma vez recorrendo a seu pensamento, as contradições entre a igualdade e a singularidade têm sido um tema familiar para os sociólogos. Se de um lado muitos defendiam o universalismo das luzes, outros defendiam a importância de se reconhecer e valorizar a particularidade. Somente nos debates atuais que o campo da sociologia teria descoberto que "o particular e o universal não se opõem" (Touraine, 2011, p. 66). Com tal afirmação, o sociólogo busca mostrar que o contexto atual traduz uma exigência de igualdade que não exclui o direito de viver para todas as categorias sociais do planeta, apontando para a importância das lutas humanitárias conduzidas por sujeitos que se opõem historicamente contra as desigualdades produzidas por questões sociais e econômicas 
que acompanham grupos sociais desde o seu nascimento. Nas palavras de Touraine (2011, p. 67), então, "combinar igualdade e diferença não é um problema simples de resolver, mas ele está no coração de nossas crenças e exerce doravante uma grande influência em nossas práticas, e notadamente em nossas práticas sociais".

Pensar as relações entre o universal e o particular, como aponta Touraine (2011), é uma questão importante para o campo da sociologia, mas como desejamos mostrar neste artigo tal discussão também deve ser considerada no campo pedagógico. De acordo com Bernard Charlot (2013, p. 117), de outra perspectiva, "a escola é universalista, pelo menos nas sociedades democráticas". O pesquisador sustenta tal afirmativa fundamentado em dois pressupostos. $\mathrm{O}$ primeiro refere-se a um dos princípios básicos do trabalho pedagógico que consiste na crença da capacidade de educabilidade de todos os seres humanos. De acordo com Charlot (2013, p. 118), "qualquer ser humano sempre vale mais do que fez e do que parece ser". O segundo pressuposto consiste na defesa de que a escola não pode deixar de ser universalista porque uma de suas funções principais seria "divulgar saberes universais e sistematizados” (Charlot, 2013, p. 118). Tais saberes, objetivamente, dependeriam de uma relação com o sistema, e não com a sensibilidade individual ou mesmo a interpretação de cada sujeito envolvido no processo educativo.

Nesse cenário, Charlot (2013) problematiza duas interpretações advindas do campo pedagógico e que teriam relação com o respeito ao particular em detrimento do universal. A primeira questão estaria associada com a importância de as instituições escolares ensinarem crianças e jovens a respeitarem as diferenças culturais. De acordo com o pesquisador, essa é uma premissa importante e não se apresenta como uma contradição ao universalismo das práticas escolares - o problema estaria na questão de quais diferenças culturais a escola deve ensinar as crianças a respeitar.

A segunda questão refere-se à necessidade de individualizar o ensino de cada aluno tendo em vista suas necessidades e seus interesses. Novamente o pesquisador afirma que tal assertiva parece coerente, mas o que significa individualizar os percursos formativos dos estudantes? Como individualizar o "ensino de princípios e saberes universais e de normas que estruturam a atividade intelectual?" (Charlot, 2013, p. 119).

Por fim, a filósofa Nadja Hermann (2008) parte de pressuposto semelhante àquele apresentado por Charlot (2013), uma vez que, em sua perspectiva, todo processo educacional "pressupõe um processo de inserção num mundo compartilhado de valores e crenças" (Hermann, 2008, p. 26), no entanto a autora parece avançar ao diagnosticar que o debate educacional não deveria se situar ou no polo da individualização ou no polo da universalização, como se tais operassem de forma excludente. Para Hermann (2008), tal debate deveria estar situado na tensão entre esses dois polos, e o não reconhecimento dessa tensão poderia nos encaminhar "à armadilha que consiste em subverter a criação do eu, remetendo-se exclusivamente a regras e padrões próprios numa auto-estilização estética”(Hermann, 2008, p. 27). Podemos inferir tomando como base o pensamento da pesquisadora brasileira que uma prática pedagógica voltada apenas para o indivíduo e seus interesses, mesmo sendo sedutora, pode produzir uma "impossibilidade de construir um ethos comum" (Hermann, 2008, p. 27). 
Considerando tais apontamentos, encaminhamo-nos para a próxima seção, em que nos propomos revisitar dois importantes trabalhos da primeira metade do século XX que possuem delineamentos distintos sobre os propósitos da educação. Se de um lado encontramos a importância de uma educação pautada na vida em comum refletindo as necessidades da sociedade, no mesmo período temos uma posição divergente defendendo a importância de a educação considerar a personalidade de cada estudante no delineamento de seu percurso formativo.

\section{ENTRE A ESCOLA REPUBLICANA FRANCESA E A SOBERANIA ENTREGUE ÀS NOVAS GERAÇÕES}

Em alguns textos publicados no início do século XX, sobretudo da sua aula inaugural na Sorbonne no ano de $1902 \mathrm{em}$ diante, Émile Durkheim procurou delinear sociologicamente o campo da educação, seja para distanciar-se de uma perspectiva idealista, seja para declinar da possibilidade de pensar a educação por uma lógica utilitarista. O sociólogo sugeria, então, que as definições em voga na virada do século esbarravam em uma interpretação única e universal do fazer educativo e, nessa direção, seu objetivo seria posicionar a educação no âmbito das práticas sociais de cada contexto e de cada período histórico. Sua abordagem, ao inserir a educação no campo dos fatos a serem analisados sociologicamente, promoveu uma ruptura nos modos de pensar essa questão. Em suas palavras,"cada sociedade, considerada em determinado momento de seu desenvolvimento, tem um sistema de educação que se impõe aos indivíduos com uma força geralmente irresistível" (Durkheim, 2013, p. 47-48).

Ao postular esse entendimento, Durkheim (2013) estabelece que não são os próprios indivíduos que determinam seu tipo de educação, nem mesmo que os seus costumes e suas ideias deverão prevalecer. Por esse prisma, tal processo é "produto da vida em comum e reflete suas necessidades. Em sua maior parte, eles são inclusive fruto das gerações anteriores" (Durkheim, 2013, p. 48). Expandindo essa reflexão, o sociólogo defende que todo sistema de educação, das variadas sociedades, apresenta duas características principais: múltiplo e uno. Evidencia-se como múltiplo na medida em que os variados agrupamentos sociais tendem a apresentar formas específicas e variadas de educar, ainda que na maioria das vezes assentada em princípios comuns. Porém, de maneira complementar, a educação forma os indivíduos de modo singular.

A clássica definição durkheimiana de educação posiciona-a como "uma socialização metódica das novas gerações” (Durkheim, 2013, p. 54). O caráter social da educação delinearia as características desejadas pela sociedade que o antecede e, por outro lado, cria as condições para que nossa individualidade se consolide. De acordo com o sociólogo, essa seria a "virtude criadora da educação"(Durkheim, 2013, p. 54), produzida no tensionamento e na complementaridade entre socialização e individualização ${ }^{2}$. Importante enaltecer também, em tais condições, que isso não suporia uma ação violenta sobre os indivíduos.

2 Essa argumentação é ampliada em Lima (2015) e em Silva (2016). 
Enquanto mostrávamos a sociedade modelando os indivíduos de acordo com suas necessidades, podia parecer que eles sofriam assim uma insuportável tirania. Porém, na realidade, eles próprios têm interesse nesta submissão, pois o novo ser que a ação coletiva edifica em cada um de nós através da educação representa o que há de melhor em nós, ou seja, o que há de propriamente humano em nós. (Durkheim, 2013, p. 58)

Em termos de organização dos sistemas de ensino e dos deveres do Estado, o sociólogo pontua ainda que a sociedade deveria assumir-se como ponto de referência para a educação. Nos marcos de uma escola pública se evitaria que a escolarização ficasse “à mercê das vontades individuais"(Durkheim, 2013, p. 62). Em suas palavras, à sociedade cabe orientar esse princípio evitando que a educação fique "a serviço de crenças particulares" e, dessa forma, "a grande alma da pátria se dividiria e se dissolveria em uma pluralidade incoerente de pequenas almas fragmentárias em conflito umas com as outras" (Durkheim, 2013, p. 62).

Objetivamente, a abordagem apresentada por Durkheim (2013) sintoniza-se com os fundamentos da escola republicana, importante debate educacional estabelecido na França desde o fim do século XIX. Todavia, o sociólogo acrescenta a variável de que os próprios indivíduos também são constituídos nesse processo, visto que, por seu prisma, o antagonismo entre indivíduo e sociedade não é correspondido no plano da vida material. Isto é,

ao querer a sociedade, o indivíduo quer a si mesmo. O objetivo e o efeito da ação que ela exerce sobre ele, principalmente através da educação, não são nem um pouco reprimi-lo, diminuí-lo, desnaturá-lo, mas sim amplificá-lo e transformá-lo em um ser verdadeiramente humano. (Durkheim, 2013, p. 61)

Afastando-se desse posicionamento, encontramos uma posição contrastante nas primeiras décadas do século XX por meio da emergência e da difusão internacional dos princípios pedagógicos progressivistas, derivados dos conhecidos movimentos da Educação Nova ${ }^{3}$. Do ponto de vista curricular, talvez o autor que tenha adquirido maior visibilidade pública e reconhecimento acadêmico tenha sido o estadunidense William Kilpatrick. Sob inspiração de John Dewey, seu orientador e principal influência intelectual, o educador realizou uma inversão nas formas de composição de uma escola democrática, deslocando seus princípios para o nível do indivíduo e para suas possibilidades de investigação. Na obra que compila sua principal construção teórica, a pedagogia de projetos, Kilpatrick agradece a seu orientador por ter aprendido a "perceber o interesse individual como ponto de partida do mistério educacional e curricular" (Kilpatrick, 2006, p. 10).

Em uma obra bastante estudada no Brasil, Educação para uma civilização em mudança, o pesquisador propõe a importância de se repensar a educação para o contexto de mudanças culturais da primeira metade do século passado. As questões dos

3 Algumas leituras da história da educação, recentemente elaboradas, contribuem para ampliar esse argumento (Hamilton, 2002; Noguera-Ramirez, 2011; Silva, 2018). 
avanços científicos, das formas de comunicação, dos processos de industrialização e dos modos de vida democráticos, em sua perspectiva, passaram a requerer novas demandas para o campo educacional. A questão de uma subjetividade aprendente, por intermédio da experiência dos estudantes, é a principal contribuição levantada pelo autor para prospectar a educação para um mundo em mudança.

Segundo o novo pensamento, devemos ter como alvo, desde que aceitemos a realidade, um tipo de indivíduo capaz de pensar e decidir por si mesmo, de pensar livremente, sem as peias de preconceitos, de decidir altruisticamente, preferindo o bem social a qualquer vantagem ou bem individual. A única finalidade que podemos aceitar será aquela que dê maior valor à personalidade de cada qual. (Kilpatrick, 1978, p. 90)

A valorização da "personalidade de cada estudante" é a base daquela que é considerada a principal construção teórica do pensamento de Kilpatrick (1978): a metodologia de projetos. Em sua abordagem, seria conveniente reposicionar as matérias escolares, reorganizando-as em um novo currículo (programa) no qual os estudantes teriam papel de decisão inalienável. A necessidade de preparar os jovens para um futuro incerto implicaria atribuir centralidade aos métodos ativos, às experiências dos estudantes e a outro perfil de professor.

Seu ponto de partida é: "O presente precisa ter a honestidade de conceber soberania de controle à nova geração" (Kilpatrick, 1978, p. 84). Aproximar a escola da vida, os conhecimentos das experiências e o pensamento da ação é visto como aspecto importante pelo educador estadunidense, sob forte inspiração deweyana. O currículo escolar delineado por Kilpatrick (1978) supõe o desenvolvimento dos estudantes mediante situações ativas.

Na verdade, porém, a nova concepção do programa é muito diversa daquela pela qual a maioria a compreende. O novo programa consiste em experiências. Usa as matérias, mas não consiste em matérias ou disciplinas feitas e acabadas. O velho programa consistia em matérias preestabelecidas, para serem aprendidas a fim de serem recitadas quando se mandasse. A essência do novo programa será levar a criança a uma situação ativa, em que ponha em função para as suas experiências presentes os melhores meios de comportamento. É no desenvolvimento desses melhores meios de comportamento que as matérias aparecem. É assim que cada geração sucessiva poderá progredir. Esse é o caminho pelo qual o mundo poderá resolver os seus problemas futuros. (Kilpatrick, 1978, p. 85)

Tais atividades dos estudantes, por essa perspectiva, seriam organizadas em "projetos". À medida que os indivíduos assumem a tarefa do progresso intelectual e moral da sociedade, é necessário que a escola tenha confiança nos alunos, porém vale destacar: "Só quando pratiquem o pensamento, a escolha e a responsabilidade é que podem aprender a pensar, a escolher e a aceitar a responsabilidade" (Kilpatrick, 1978 , p. 87). A capacidade de escolha torna-se um vetor para as aprendizagens 
individuais, e, via de regra, por meio da reconstrução das experiências atenderemos às condições advindas de uma civilização em mudança.

O debate pedagógico estabelecido na primeira metade do século passado se inscreve na tensão permanente entre os marcos da escola republicana para todos e as variadas abordagens centradas na atividade dos estudantes. A contemporaneidade pedagógica, dessa forma, configura-se na tensão entre privilegiar os estudantes ou formar o cidadão republicano. Ao longo do século, essa questão adquiriu novas nuanças: seja pela crise da institucionalidade da escola, seja pela própria emergência dos diferencialismos pedagógicos.

Para continuar esse campo de problematizações, na próxima seção avançamos em um século nossas análises para descrever como essa questão em torno da diferenciação pedagógica se inscreve na literatura de nosso tempo e, com base nela, traçar algumas reflexões provisórias que consideramos relevantes para a educação contemporânea.

\section{ENTRE A INDIVIDUALIZAÇÃO DAS APRENDIZAGENS E A SUSPENSÃO DAS DIFERENÇAS}

As pedagogias diferenciadas são uma herança importante dos movimentos escolanovistas, porém foi no decorrer da segunda metade do século XX que, efetivamente, uma intensa literatura pedagógica passou a defender dispositivos e instrumentos que diferencialmente atendiam aos sujeitos escolares. Conforme Perrenoud (2000, p. 18), "as pedagogias diferenciadas inspiram-se, em geral, em uma revolta contra o fracasso escolar e contra as desigualdades". Perante os dilemas da escolarização em massa, emergiram os variados debates sobre o nomeado "fracasso escolar", ora com ênfase na incapacidade dos estudantes, ora com ênfase na exclusão decorrente da própria organização do trabalho pedagógico (Charlot, 2009; Silva e Silva, 2017).

Novos modos de planejar e avaliar, novos procedimentos de ensino e de agrupamento dos estudantes, novos regimes de organização dos tempos e espaços escolares tornam-se recorrentes nessas pedagogias. A consideração dos diferentes ritmos e modos de aprendizagem configura-se como um imperativo ${ }^{4}$. Em tais condições, as pedagogias diferenciadas assumiram como tarefa a individualização permanente dos percursos de formação.

A pedagogia diferenciada origina uma nova abordagem, mais centrada no aprendiz e em seu itinerário: a individualização dos percursos de formação. Avaliam-se os limites da ação em uma classe fechada em quatro paredes e dentro de um programa anual; trabalha-se sobre as estruturas que tornam possíveis dispositivos mais favoráveis à diferenciação. (Perrenoud, 2000, p. 44)

4 Em importante exercício analítico, Lopes (2009) expõe que a própria noção de inclusão pode ser lida como um imperativo. 
O principal problema que as pedagogias diferenciadas enfrentam, de acordo com Perrenoud (2000), diz respeito aos modos como as crianças e os jovens aprendem. O reposicionamento do estudante no centro do processo formativo implica pensar que a diferenciação se torna "o cerne da ação pedagógica" (Perrenoud, 2000, p. 44). A diferenciação precisaria ser problematizada, ampliando seu escopo interventivo para abarcar as questões culturais, contextuais e demais elementos não cognitivos. Em outras palavras, torna-se desejável um esforço na direção do atendimento das especificidades de cada estudante.

Em termos curriculares, emergem e consolidam-se a individualização e a otimização das situações de aprendizagem.

Na escola primária ou no ensino médio, o domínio da individualização dos percursos visa, sobretudo, ao não-aumento das desigualdades em relação à formação. Trata-se, pois, de enfatizar as discriminações positivas, de favorecer os desfavorecidos de sempre contra uma individualização selvagem que aumenta as variações ou, pelo menos, não contribui para sua redução. (Perrenoud, 2000, p. 91)

Se, como mostra Perrenoud (2000), as pedagogias diferenciadas buscam como principal objetivo diminuir as desigualdades, sejam elas educacionais, sejam sociais, por meio de estratégias de discriminação positiva que considerem o atendimento às necessidades específicas de cada estudante, permitindo que ele avance nos seus conhecimentos escolares, tivemos no mesmo período histórico um conjunto de autores que, ao colocar a diferenciação pedagógica e a individualização dos percursos formativos no banco dos réus, apontavam para o fim da escola como espaço democrático e para a ampliação das desigualdades como principais consequências dessas práticas pedagógicas.

A obra Em defesa da escola, escrita pelos filósofos Jan Masschelein e Maarten Simons, promove uma intensa defesa da pertinência e da atualidade da instituição escolar. Em um texto de grande beleza e com significativo potencial político, os autores propõem a revitalização da escola moderna, revisitando suas possibilidades de garantia de tempo livre e de oferta de conhecimentos comuns, independentemente de seus públicos. O potencial democrático da escola estaria em suas potencialidades endógenas, isto é, naquilo que ela é capaz de realizar no interior de seus muros. Seria necessário garantir a continuidade da forma-escola.

$\mathrm{Na}$ direção de construir uma defesa da referida instituição, o primeiro (e mais importante) argumento utilizado pelos autores é a questão da suspensão que a escola conseguiria engendrar para cumprir sua tarefa pública. Em suas palavras, "muito simplesmente, isso significa que a escola dá as pessoas a chance (temporariamente, por um curto espaço de tempo) de deixar o seu passado e os antecedentes familiares para trás e se tornarem um aluno como qualquer outro" (Masschelein e Simons, 2014b, p. 31). A escola, ao garantir tempo livre para o estudo aos variados segmentos da população, precisaria criar um novo tempo, no qual os estudantes deixariam do lado de fora da escola tudo o que obstaculizasse a aprendizagem. Os autores não 
defendem que a suspensão seja uma tentativa de ignorar as variadas diferenças que perfazem os fazeres escolares.

Suspender não significa destruir ou ignorar, mas "evitar temporariamente estar na força ou no efeito". A educação como forma de suspensão não está destruindo ou negando nada, por exemplo o passado ou as instituições, mas está desorientando as instituições, interrompendo o passado. As necessidades e obrigações das profissões, os imperativos de conhecimento, as demandas da sociedade, o fardo da família, os projetos para o futuro; tudo está aí ou pode estar aí, mas em condição de flutuação. (Masschelein e Simons, 2014b, p. 287-288)

Em uma aparente retomada do idealismo pedagógico, Masschelein e Simons defendem ainda que a escola "é o tempo e o espaço onde os alunos podem deixar para lá todos os tipos de regras e expectativas sociológicas, econômicas e relacionadas à cultura" (Masschelein e Simons, 2014b, p. 35). Na percepção dos autores, por meio da suspensão e da promoção do tempo livre a escola estaria mais próxima de instaurar a igualdade em seu cotidiano. Mais que isso, postula-se a possibilidade de repensar a própria ideia de igualdade.

Para os autores, então, as pedagogias contemporâneas teriam como objetivo principal "a maximização dos talentos e capacidades de todos e sobre o estímulo de potenciais, o que está relacionado ao desenvolvimento de competências e à oferta de oportunidades iguais" (Masschelein e Simons, 2014a, p. 98). Assim, buscariam "tornar possível aos jovens com diferentes perfis que desenvolvam seus talentos ao máximo. Além de oferecer às escolas um alto grau de autonomia" (Masschelein e Simons, 2014a, p. 100). O problema apontado consistiria no fato de que em tais políticas a questão da desigualdade não seria colocada em questão. A desigualdade consistiria, para tais pedagogias, não apenas um pressuposto de onde se parte, mas também seria constantemente verificada e reificada por tais práticas pedagógicas. Assim, seria necessário inverter a lógica e propor "uma história que não tenha início na desigualdade, mas na igualdade" (Masschelein e Simons, 2014a, p. 105). Masschelein e Simons (2014a, p. 105) defendem que "a democratização da escola não estaria ligada a oportunidades e acessos iguais, mas momentos de igualdade relacionados à estrutura espaço/tempos da própria escola".

As leituras de Perrenoud e Masschelein e Simons, em contraste, permitem-nos avançar na resposta à interrogação mobilizadora de nosso estudo: por que precisamos da diferenciação pedagógica? Com Perrenoud (2000), a diferenciação supõe a otimização das situações de aprendizagem. Com Masschelein e Simons (2015), ela torna-se desnecessária, visto que a escola é autorreferente. Parece-nos que novamente estamos diante do dilema estabelecido no início do último século, porém atualizado: a referência orientadora das aprendizagens é o próprio indivíduo enquanto aprendente ou são as potencialidades formativas inerentes à instituição? Precisaríamos escolher entre privilegiar os indivíduos ou as lógicas institucionais no decorrer do processo formativo? Ao atribuirmos centralidade às aprendizagens individuais, inviabilizamos as experiências democráticas na escola? Para concluir, buscamos novos argumentos inspirados na 
sociologia da educação de Danilo Martuccelli (apud Nobile e Ferrada, 2015), anteriormente mencionado, assim como nos escritos pedagógicos tardios de Philippe Meirieu (2006).

\section{ALGUMAS PROVOCAÇÕES FINAIS E UMA SÍNTESE}

Para produzirmos um primeiro campo de tensionamentos em torno da questão orientadora deste ensaio, fazemos uso das considerações sociológicas derivadas dos estudos de Danilo Martuccelli (2011). Conforme o autor, referindo-se ao contexto francês, a seleção social que perfazia o ingresso da instituição escolar era movida por elementos exteriores. Os meios sociais mais abastados, determinadas elites culturais ou modos de vida urbanos sinalizavam os candidatos mais potentes, para as melhores escolas. As demais crianças e jovens frequentavam um sistema intermediário, reservando-se aos filhos dos populares as escolas primárias. No entanto, destaca Martuccelli (2011), a escola republicana francesa era animada por um projeto comum: "Desenvolver a consciência nacional moderna do cidadão" (Martuccelli, 2011, p. 291).

Em outras palavras, ainda que mobilizada por lógicas diferenciadas, a escola republicana francesa organizava-se com base em um projeto comum. Com a massificação dos sistemas de ensino e o prolongamento do tempo de escolaridade, por volta dos anos de 1970, novos mecanismos de seleção começaram a ser mobilizados por meio de "uma forte segmentação da oferta e da chegada de novos alunos que desestabilizam os ajustamentos tácitos próprios do antigo sistema dividido" (Martuccelli, 2011, p. 291). Uma nova economia simbólica dos diplomas foi engendrada, coadunada à revalorização da infância e da juventude. Conforme Martuccelli (2011, p. 292), "a cultura educativa da sociedade francesa se transforma, concedendo à infância e à juventude um novo reconhecimento e uma nova autonomia”.

Conforme tal analítica sociológica, percebe-se uma transição para um novo arranjo institucional que acentua as possibilidades de individualização das trajetórias escolares.

Num universo escolar institucionalmente unificado, mas socialmente diversificado, onde cada indivíduo torna-se responsável por seu próprio destino escolar, a tendência à individualização dos percursos se acentua. Doravante, cada ator é submetido a um conjunto de provas que ele mesmo é obrigado a honrar, e que pode assumir diferentes contornos segundo o lugar dos alunos no sistema educativo, seus recursos culturais, suas socializações familiares, mas igualmente seu sexo, sua nacionalidade ou o tipo de escola que frequenta. (Martuccelli, 2011, p. 292)

No que se refere ao contexto latino-americano, Martuccelli (2011) descreve que as condições são mais perversas na medida em que o Estado nunca protegeu seus cidadãos aos moldes modernos. A principal decorrência desse argumento, ainda segundo o sociólogo, é que "o indivíduo não é mais imaginado herdeiro de uma posição social, ele é tornado responsável pelas próprias aquisições” (Martuccelli, 
2011, p. 292). No limite, a individualização dos percursos tende a intensificar as desigualdades escolares, tendo em vista que é matizada pela responsabilização individual dos estudantes e pelo desencadeamento de novas experiências de injustiça. Ingressar no debate entre individualização e socialização escolhendo um dos polos pode parecer uma solução pouco razoável.

Ainda que Philippe Meirieu (2006) tenha sido um dos criadores da noção de "pedagogias diferenciadas", seus escritos tardios evidenciam uma preocupação interessante: a necessidade de também levar em consideração a formação do cidadão. Reconhecendo a centralidade das questões individuais, o pedagogo sinaliza para uma dimensão silenciada em seus estudos anteriores: a compreensão de que "a Escola institui um certo tipo de relação - com os saberes que ela ensina e com os grupos que ela escolariza - que a especifica em meio a uma infinidade de modos de agrupamento inventados pelos homens" (Meirieu, 2006, p. 68). Sendo a escola um contexto educativo específico, sugere o autor que a aprendizagem precisaria ser dimensionada com base em valores específicos, tais como: "O reconhecimento da alteridade, a exigência de precisão, de rigor e de verdade, a aprendizagem conjunta de constituição do bem comum e da capacidade de "pensar por si mesmo"' (Meirieu, 2006, p. 68).

$\mathrm{O}$ primeiro valor assinalado pelo pedagogo remete-se à percepção da escola como uma instituição que privilegia o encontro com a alteridade. Mesmo que a criança ocupe o centro do processo pedagógico, explica Meirieu (2006), a instituição precisaria auxiliá-la a não desejar tornar-se o "centro do mundo". Ou seja, o desafio estaria em combater "a propensão de cada um a reduzir o mundo ao seu universo pessoal" (Meirieu, 2006, p. 70). O segundo valor apresentado pelo teórico é revitalizar os debates sobre nossa relação com o saber, ou seja, instalar "progressivamente no centro da sala de aula uma conduta que faz da exigência de precisão, de justeza, de rigor e de verdade a regra explícita do trabalho coletivo" (Meirieu, 2006, p. 71). Por fim, o terceiro valor apresentado - e aquele que melhor dialoga com a questão orientadora deste ensaio - consiste no perfil da escola na instituição de uma sociedade democrática. Educar para uma sociedade democrática, então, implicaria valorizar as individualidades, todavia distanciando-se de individualismos e comunitarismos.

A Escola poderia então ter um papel decisivo aqui. Desde que tome a pulso um duplo trabalho: de um lado, o de ajudar cada aluno a escapar de todas as formas de tribalismo que imponham a conformidade à norma e impeçam qualquer liberdade de pensamento; e, de outro lado, o de ensinar a cada um, permanentemente, a se descentrar de suas preocupações imediatas e de seus interesses pessoais para se associar a outros e caminhar no sentido do universal. Duplo trabalho. Dupla exigência. $\mathrm{E}$ as duas faces da mesma peça do quebra-cabeça, a peça que falta, ou é apenas esboçada, de nossa modernidade: uma instituição democrática. (Meirieu, 2006, p. 73)

Argumenta o pedagogo que precisamos escapar dos tribalismos e comunitarismos, ao mesmo tempo em que é necessário distanciar-se das possibilidades 
de fazer da pedagogia uma simples condução individualizada. Em outras palavras, considerar as demandas da formação individual nos marcos de uma sociedade democrática parece ser o desafio apresentado por Meirieu (2006). Um tensionamento emergente desse debate remete-se às relações com a desigualdade, questão incontornável para responder à interrogação sobre a necessidade das pedagogias diferenciadas. Objetivamente, compreender a importância de olharmos com atenção para as necessidades individuais dos nossos alunos não deveria implicar uma omissão associada a um trabalho coletivo, democrático e que amplie as possibilidades de jovens e crianças se relacionarem com o conhecimento culturalmente acumulado pela sociedade. No âmbito da pedagogia, mais do que nos posicionarmos em um dos polos desse debate, advogamos pela justaposição equilibrada de ambos - de maneira que efetivamente possamos nomear o que fazemos como trabalho pedagógico.

Para fins deste texto, poderíamos afirmar que uma ênfase exclusiva na sociedade pode se converter em violência (na forma dos variados totalitarismos engendrados no século $\mathrm{XX}$ ), ao mesmo tempo em que uma ênfase exclusiva no indivíduo, além de pedagogicamente irresponsável, bloqueia as possibilidades de diálogo, de convivência democrática e de constituição de uma pauta formativa comum. Parafraseando a epígrafe escolhida para a abertura deste artigo, o nosso desafio como professores parece situar-se na construção de uma pedagogia que auxilie os nossos alunos a entrarem no novo mundo por meio de uma consciência coletiva e, paradoxalmente, também garantir a vontade de cada aluno na defesa de sua identidade própria.

\section{REFERÊNCIAS}

AQUINO, J. G. Da autoridade pedagógica à amizade intelectual: uma plataforma para o éthos docente. São Paulo: Cortez, 2014.

AZANHA, J.M.P. Democratização do ensino: vicissitudes da ideia no ensino paulista. Educação e Pesquisa, São Paulo, v. 30, n. 2, p. 335-344, 2004. http://dx.doi.org/10.1590/ S1517-97022004000200012

BIESTA, G. Para além da aprendizagem: educação democrática para um futuro humano. Belo Horizonte: Autêntica, 2013.

BIESTA, G. Devolver la enseñanza a la educación. Una respuesta a la desaparición del maestro. Pedagogia y Saberes, Bogotá, n. 44, p. 119-129, 2016. https://doi.org/10.17 227/01212494.44pys119.129

CHARLOT, B. A escola e o trabalho dos alunos. Sísifo: Revista de Ciências da Educação, n. 10, p. 89-96, 2009.

CHARLOT, B. Da relação com o saber às práticas educativas. São Paulo: Cortez, 2013.

DURKHEIM, É. Educação e Sociologia. 4. ed. Petrópolis: Vozes, 2013.

FOUCAULT, M. História da Sexualidade 2: o uso dos prazeres. 2. ed. São Paulo: Paz e Terra, 2014.

HAMILTON, D. O Revivescimento da Aprendizagem? Educação e Sociedade, v. 23, n. 78, p. 187-198, 2002. http://dx.doi.org/10.1590/S0101-73302002000200011 
HERMANN, N. Ética: a aprendizagem da arte de viver. Educação e Sociedade, Campinas, v. 29, n. 102, p. 15-32, 2008.

KILPATRICK, W. Educação para uma civilização em mudança. 16. ed. São Paulo: Melhoramentos, 1978.

KILPATRICK, W. O Método de Projeto. Viseu: Livraria Pretexto e Edições Pedago, 2006.

LIMA, A. L.Administração das diferenças individuais na escola: um estudo histórico do discurso da Psicologia sobre as crianças que não aprendem. In: CATANI, D.; GATTI JR., D. (orgs.). O que faz a escola? Elementos para a compreensão da vida escolar. Uberlândia: EDUFU, 2015. p. 17-49.

LOPES, M. C. Políticas de inclusão e governamentalidade. Educação e Realidade, v. 34, n. 2, p. 153-169, 2009.

MARTUCCELLI, D. Efeitos sociais e políticos da educação. In: VAN ZANTEN, Agnes (Coord.). Dicionário de Educação. Petrópolis: Vozes, 2011. p. 291-295.

MASSCHELEIN, J.; SIMONS, M. A pedagogia, a democracia, a escola. Belo Horizonte: Autêntica, 2014a.

MASSCHELEIN, J.; SIMONS, M. Em defesa da escola. Belo Horizonte: Autêntica, 2014b.

MASSCHELEIN, J.; SIMONS, M. Nossas crianças não são nossas crianças: ou porque a escolar não é um ambiente de aprendizagem. Revista Sul-Americana de Filosofia e Educação, n. 23, p. 282-297, 2015.

MEIRIEU, P. Carta a um jovem professor. Porto Alegre: Artmed, 2006.

NARODOWSKI, M. Un mundo sin adultos. Buenos Aires: Debate, 2016.

NOBILE, M.; FERRADA, R. Entrevista a Danilo Martuccelli: La singularización en las sociedades contemporáneas: claves para su comprensión. Propuesta Educativa, Buenos Aires, n. 43, p. 99-112, jun. 2015.

NOGUERA-RAMIREZ, C. Pedagogia e governamentalidade ou Da Modernidade como uma sociedade educativa. Belo Horizonte: Autêntica, 2011.

PERRENOUD, P. Pedagogia diferenciada. Porto Alegre: Artmed, 2000.

RENAUT, A. O indivíduo: reflexões acerca da Filosofia do Sujeito. Rio de Janeiro: Difel, 1998.

SCHERER, R. P. Centralidade na avaliação e educação customizada: o fim da escola como espaço para transmissão de uma “cultura comum”? Contexto \& Educação, Ijuí, v. 32, n. 102, p. 118-144, 2017. https://doi.org/10.21527/2179-1309.2017.102.118-144 SCHERER, R. P.; GRÄFF, P. Das adaptações às flexibilizações curriculares: uma análise de documentos legais e revistas pedagógicas. Revista e-Curriculum, São Paulo, v. 15, n. 2, p. 376-400, 2017. https://doi.org/10.23925/1809-3876.2017v15i2p376-400 SILVA, R. R. D. da. Políticas de constituição do conhecimento escolar para o Ensino Médio no Rio Grande do Sul: uma analítica de currículo. Educação em Revista, Belo Horizonte, v. 30, n. 1, p. 127-156, mar. 2014. http://dx.doi.org/10.1590/S010246982014000100006 
SILVA, R. R. D. da. Currículo, conhecimento e transmissão cultural: contribuições para uma teorização pedagógica contemporânea. Cadernos de Pesquisa, v. 46, n. 159, p. 158-182, 2016. http://dx.doi.org/10.1590/198053143507

SILVA, R. R. D. da. Estetização Pedagógica, Aprendizagens Ativas e Práticas Curriculares no Brasil. Educação e Realidade, v. 43, n. 2, p. 551-568, 2018. http:// dx.doi.org/10.1590/2175-623667743

SILVA, R. R. D. da; SILVA, R. Currículo e conhecimento das políticas contemporâneas de ampliação da jornada escolar. In: CARVALHO, R.; CAMOZZATO, V. (orgs.). Educação, escola e cultura contemporânea: perspectivas investigativas. Curitiba: Intersaberes, 2017. p. 165-199.

TOURAINE, A. Pensar outramente: o discurso interpretativo dominante. Petrópolis: Vozes, 2009.

TOURAINE, A. Após a Crise: a decomposição da vida social e o surgimento de atores não sociais. Petrópolis: Vozes, 2011.

\section{SOBRE OS AUTORES}

Roberto Rafael Dias da Silva é doutor em educação pela Universidade do Vale do Rio dos Sinos (Unisinos). Professor da mesma instituição. E-mail: robertoddsilva@yahoo.com.br

Renata Porcher Scherer é doutoranda em educação pela Universidade do Vale do Rio dos Sinos (Unisinos). E-mail: renatapscherer@gmail.com

Recebido em 9 de setembro de 2018 Aprovado em 16 de maio de 2019 